\title{
LAST NIGHT OF THE YEAR WE REMEMBERED OUR DESIRES
}

my not dancing represents me

I go toward it to prove my body

it's dark here enough to think I could merge

these fluid souls with my joy

I could own, could pet

the shifting figure I dread

my body truly

time goes dancing to sleep with my hesitance

beauty points out her head

smashed as the position apparent

again I have chosen to want 